\title{
Polyamide 66 Polymorphic Single Polymer Composites
}

\author{
Miro Duhovic, Philipp Maitrot and Stoyko Fakirov*
}

Centre for Advanced Composite Materials, Department of Mechanical Engineering, The University of Auckland, Private Bag 92019, Auckland, New Zealand

\begin{abstract}
Exploring the polymorphism phenomenon of polyamide 66 (PA 66) a single polymer composite (SPC) was prepared. The matrix was obtained via compression molding and quenching in ice water expecting to comprise the modification with lower melting temperature $\left(T_{m}\right)$. The reinforcement was commercial textile yarn of PA 66, characterized by a higher $T_{m}$. Layers of the yarn were sandwiched between matrix films and compression molded at $250{ }^{\circ} \mathrm{C}$, i.e. $10^{\circ} \mathrm{C}$ below $T_{m}$ of the reinforcement. SEM observations revealed the layered structure of SPC as well as a good adhesion between the composite components due to surface premelting. The tensile testing showed, as compared with the matrix, an increase of the initial modulus by $28 \%$ and of the tensile strength by $160 \%$ when the reinforcing component of the SPC amounted to only $20 \mathrm{wt} \%$. Optimization of the preparation conditions, including variation of the matrix/reinforcement ratio as well as trialing of other polyamides, is in progress.
\end{abstract}

Keywords: Polymorphism, single polymer composites, mechanical properties.

\section{INTRODUCTION}

In the field of composite science and technology a parameter of paramount importance is the adhesion between the matrix and reinforcement, in addition to the aspect ratio of the latter. The adhesion problem exists because composites are, as a rule, two-component systems differing in their chemical composition. This could be overcome to a significant extent if the matrix and the reinforcement are of the same chemical composition, e.g. by the preparation of single polymer composites (SPC).

The first experiments in this direction were reported by Capiati and Porter [1], however a fundamental study of SPC was carried out by Ward et al. [2-8]. Ward developed and commercialized a patented technology for the manufacture of single polymer composites called "hot compaction" where only one constituent is used [2]. This technology explores an inherent property of polymers, namely, the fact that the semi-crystalline polymers always comprise of crystallites with varying perfection and thus having different melting temperature $\left(T_{m}\right)$ resulting in a melting interval instead of a "melting point". During the hot compaction the highly drawn fibers or tapes are treated at a temperature being the $T_{m}$ of the less perfect crystallites and representing the start of the melting interval. In this way, due mostly to a surface partial melting, the aligned pressed fibers or filaments stick together, creating an isotropic "matrix" component of the SPC. A peculiarity of this approach is the domination of the highly oriented reinforcement amounting to $80 \mathrm{wt} \%$ [3]. Using this technology Ward and coworkers succeeded to prepare SPC from a series of polymers such as polyethylene [4], polypropylene [5], poly(ethylene terephthalate) [6], poly(ethylene naphthalate), polyamide 66 [3] summarized in ref. [8]. They

*Address correspondence to this author at the Centre for Advanced Composite Materials, Department of Mechanical Engineering, The University of Auckland, Private Bag 92019, Auckland, New Zealand; Tel: +64 9373 7599 ext. 84543; Fax: +64 9367 7181; E-mail: s.fakirov@auckland.ac.nz reported improvements in the mechanical properties of several times as compared with the isotropic, non-reinforced polymers.

A different way of achieving the same target was followed by Karger-Kocsis [9] who explored the strong tendency of some polymers to crystallize in two or more polymorphic modifications distinguished by different properties including the $T_{m}$-value. He patented this method for preparation of polymorphic SPCs from PP calling them "all-PP composites" [9-12]. The lower melting modification (matrix) was prepared using an appropriate nucleating agent and the reinforcement was the PP modification with higher $T_{m}$. Again, compression molding was used to manufacture the composite at a temperature between the $T_{m}$ of the two polymorphic modifications of PP. It is also worth mentioning that this approach allows preparation of single polymer composite materials with a composition matrix/reinforcement closer to that of the traditional glass fiber reinforced polymer composites.

Because of the environmental impact of glass fiber reinforced polymer composites, particularly in the European car manufacturing industry [13], the preparation of single polymer composites is becoming an attractive option. For this reason, the present study attempts to apply the second approach for the preparation of SPC using other polymers characterized by an extremely high ability to form polymorphic modifications. These are the polyamides [14]. It is interesting to note that, for example, polyamide 6 (PA 6) quenched from its melt, crystallizes in the $\gamma$-modification, while at higher temperatures and/or during drawing it undergoes recrystallization in the higher-melting $\alpha$-modification. This polymorphic transition takes place in such a smooth way that the existence of the $\gamma$-modification cannot be detected during the heating in the differential scanning calorimeter. Only after applying a chemical cross-linking in the amorphous areas before scanning, Fakirov and Avramova [15] succeeded to prevent the recrystallization 
process and thus even to determine the equilibrium melting temperature $\left(T_{m}{ }^{o}\right)$ of the $\gamma$-modification of PA 6 amounting to $T_{m}{ }^{o}=208^{\circ} \mathrm{C}$ (against $T_{m}{ }^{o}=278^{\circ} \mathrm{C}$ of the $\alpha$-modification) [15].

It should be mentioned here that in the present study no particular analysis for the identification of the polymorphic modifications has been carried out. Using the preparation conditions described in the literature for the two modifications, it is expected that one or the other polymorphic modification dominates in the two manufactured samples.

\section{MATERIALS AND METHODOLOGY}

For the purposes of the current study, a polyamide 66 (PA 66) type EMS-Grivory Grilon ${ }^{\circledR}$ T300GM, supplied by EMS, Germany, as pellets with a melt flow index of 160 $\mathrm{g} / 10$ min was used as the matrix. PA 66 commercial texturised yarn Timbrelle ${ }^{\circledR}$ dtex $44 \mathrm{f} 13 \times 2$, supplied by TWD Fibres, Germany, played the role of reinforcement.

The matrix was prepared in the form of a thin film (thickness of $\sim 60 \mu \mathrm{m}$ ) by means of compression molding at $270^{\circ} \mathrm{C}$ for $5 \mathrm{~min}$ and at a pressure of about $35 \mathrm{MPa}$, followed by quenching in ice water together with the covering Teflon films. The reinforcing yarn of continuous filaments was wound onto a metal frame using a lathe. A matrix film was then placed between the two yarn layers along with two further films on either side of the frame. The compression molding was carried out at $250{ }^{\circ} \mathrm{C}$ for $5 \mathrm{~min}$ at a pressure of $\sim 30 \mathrm{MPa}$. The pressure was maintained during the cooling down process. In this way films with a thickness of $\sim 200 \mu \mathrm{m}$ were prepared. All the materials used were dried in a vacuum oven at $80{ }^{\circ} \mathrm{C}$ for $24 \mathrm{~h}$ before being subjected to any thermal treatment.

The $T_{m}$ values and the melting intervals, which were of particular importance in this study, along with the degree of crystallinity $\left(w_{c}(\mathrm{DSC})\right)$ were determined using a differential scanning calorimeter (DSC) of type DSC Q 1000 of TA Instruments. Typically 6 to $8 \mathrm{mg}$ of material was subjected to scanning at a heating rate of $10{ }^{\circ} \mathrm{C} / \mathrm{min}$. The $w_{c}(\mathrm{DSC})$ ) was calculated by means of the equation:

$\left.w_{c}(\mathrm{DSC})\right)=\Delta H_{\text {exp }} / \Delta H^{\circ}$

where $\Delta H_{\text {exp }}$ and $\Delta H^{\circ}$ are the experimentally measured and the ideal (for $100 \%$ crystalline sample) values of the heat of fusion, respectively. For $\Delta H^{\circ}$ the value of $190.50 \mathrm{~J} / \mathrm{g}$ [16] was used.

Scanning electron microscopy (SEM) was applied for observation of the cryofractured surfaces of the composite samples. For this purpose the respective sample was submerged in liquid Nitrogen, where the fracturing took place. The observations were performed on a Philips XL30S instrument with an acceleration voltage of $5 \mathrm{kV}$.

The mechanical performance of the starting isotropic films of PA 66 (matrix) and the prepared polymorphic SPC was evaluated in tensile mode using an Instron 5567 machine equipped with a load cell interface, model SN-1000N, gauge length of $50 \mathrm{~mm}$ and cross-head speed of $5 \mathrm{~mm} / \mathrm{min}$ at room temperature and $50 \%$ humidity. The testing was performed after room conditioning of the samples for two weeks since the absorbed moisture $(2.2 \%$ as an equilibrium amount) has a dramatic effect on the mechanical properties as demonstrated by Ward and Hine just for the same polymer [3]. The testing was performed according to ASTM D882 on strips $15 \mathrm{~mm}$ wide punched by means of a die from the compression molded films. The results of six specimens were averaged for each sample.

\section{RESULTS AND DISCUSSION}

Fig. (1) shows the DSC melting endotherms of the starting materials, the PA 66 yarn (reinforcement), Fig. (1a), and the isotropic PA 66 film (matrix), Fig. (1b) as well as the polymorphic SPC, Fig. (1c). There are two important observations in this case: (i) the two starting materials melt at different temperatures in accordance with the expectation, $260^{\circ} \mathrm{C}$ for the reinforcement and $250^{\circ} \mathrm{C}$ for the matrix, Figs. (1a) and (1b) (the lower-melting peak), respectively, and (ii) the matrix film melts at temperatures being at the start of the melting process of the reinforcing filaments $\left(250^{\circ} \mathrm{C}\right)$. Both observations are very important for the manufacturing process of the single polymer composites. Furthermore, the actual melting temperature of the reinforcing filaments during compression molding is expected to be significantly higher as the filaments being wound on a metal frame are constrained. Ward and Hine found a difference in the onset of melting due to the constraining of the fibers of around $10^{\circ} \mathrm{C}$ for commercial PA 66 fibers [3].

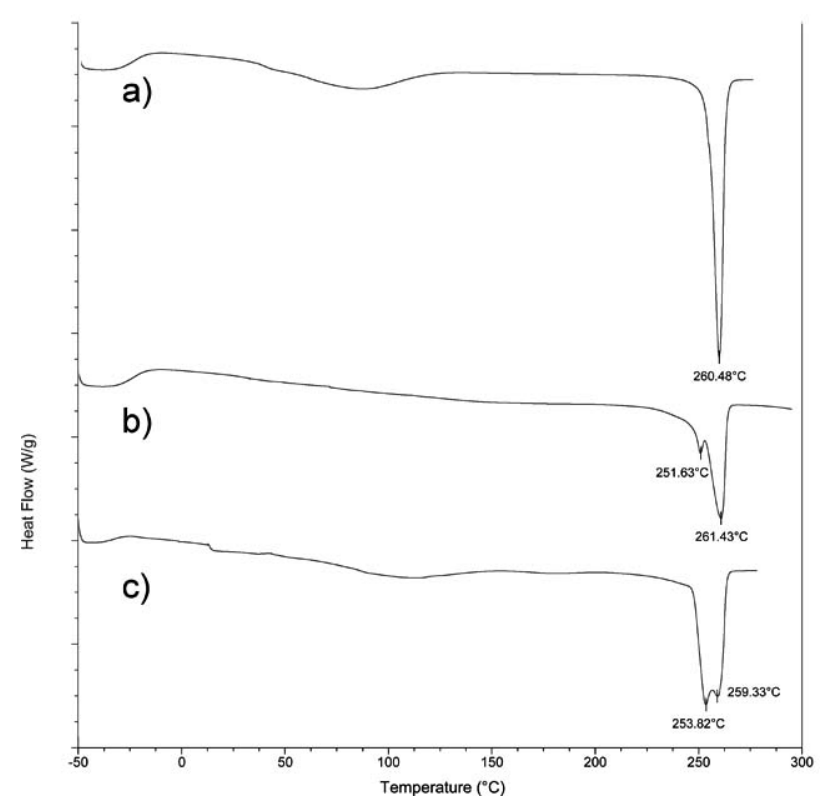

Fig. (1). DSC heating endotherms of: a) - PA 66 multifilament (reinforcement), b) - PA 66 matrix film, c) - polymorphic single polymer composite of PA 66.

The degree of crystallinity of the starting materials is also different, $28 \%$ for the matrix (calculated from the area of the lower melting peak of curve (b) in Fig. 1) and $41 \%$ for the reinforcement. This difference in the $w_{c}(\mathrm{DSC})$ ) values is also in favor of the SPC manufacturing process since it enhances the wetting of the reinforcing filaments. An indication of the wetting quality can be gained by microscopic inspection.

In Fig. (2) the SEM micrographs of the cryofractured surface of SPC, taken at various magnifications, are shown. From Fig. (2a) it is quite evident that the reinforcing fila- 

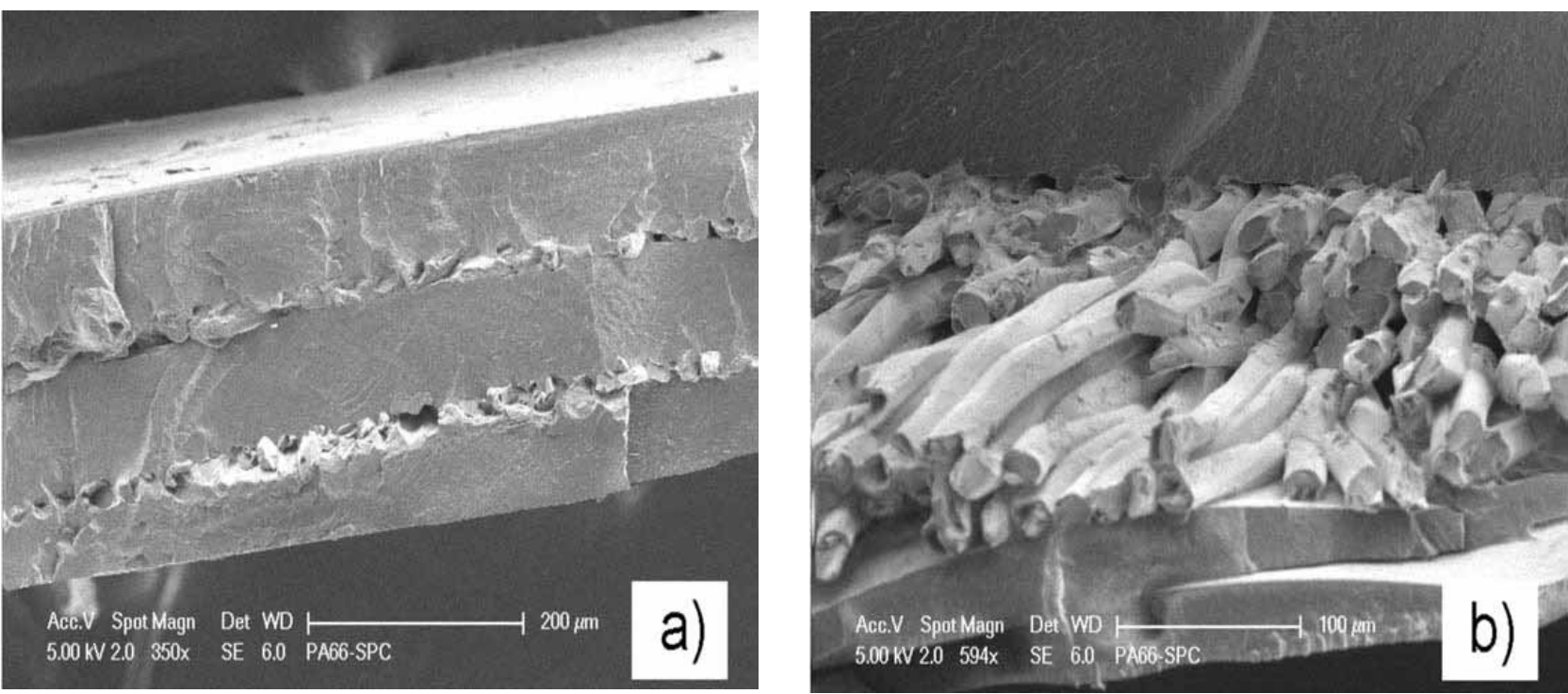

Fig. (2). SEM micrographs of cryofractured surfaces of polymorphic single polymer composite of PA 66: a) - demonstration of the layered structure of the prepared SPC, b) - demonstration of the wetting as result of surface pre-melting.

ments are preserved during the compression molding of the SPC. A well expressed layered structure of the composite material can be seen.

In regards to the wetting quality, this could be judged from Fig. (2b) where again a micrograph of the cryofractured surface is displayed but taken at higher magnification. Due to the applied pressure and surface pre-melting, the filaments sandwiched between the matrix films are connected to one another as well as with the matrix films, assuming a good adhesion quality between the two composite constituents, Fig. (2b).

After demonstrating that the prepared samples have the typical structure of a fiber reinforced composite with a layered structure, Fig. (2), it was of interest to check to what extent their mechanical performance satisfies the requirements for such materials, i.e. if any reinforcement could be observed. The results of the static tensile tests are summarized in Table 1 together with the results of Ward and Hine [3] for the SPC of the same polymer but using the hot compaction technique and one constituent.
As compared with the starting isotropic film (matrix), an improvement in the initial modulus of $28 \%$ and much more for the stress at break (increase of 163\%) is achieved for the SPC (Table 1), i.e. one really deals with a single polymer composite expectedly of the polymorphic type. Of particular importance in this case is the fact that the increase of the initial modulus is smaller than that of the hot compacted SPC based on the same polymer [3]. This difference could be related with the matrix/reinforcement ratio of the SPC prepared in the two different ways. In the case of hot compaction the reinforcement $(80 \mathrm{wt} \%)$ strongly dominates, Table 1, [3], while in the polymorphic SPC the reinforcement only amounts to $20 \mathrm{wt} \%$ (Table 1). In this respect it seems important to note that for the hot compacted samples the modulus of the oriented phase is three times higher than that of the matrix-phase modulus (5.8 against $1.9 \mathrm{GPa}$, both in a wet state [3]). Further, in accordance with the expectation, the polymorphic PA 66 composite samples show a lower (by $25 \%)$ elongation at break as compared with the nonreinforced PA 66 (Table 1). In addition, all specimens, those of the matrix film and of the composite specimens, demon-

Table 1. Data of the Static-Mechanical Tests in Tensile Mode for PA 66 Polymorphic SPC (Two Constituents) and for Hot Compacted PA 66 SPC (One Constituent) [3]

\begin{tabular}{|c|c|c|c|c|c|c|c|c|}
\hline & \multicolumn{4}{|c|}{ This study } & \multicolumn{4}{|c|}{ Hot compaction [3] } \\
\hline & Matrix & SPC & Change & $\begin{array}{c}\text { Reinforcement } \\
(\%)(\text { by wt.) }\end{array}$ & Matrix & SPC & Change & (\%) (by wt.) \\
\hline Compaction temp. $\left({ }^{\circ} \mathrm{C}\right)$ & 270 & 250 & - & - & - & - & +261 & - \\
\hline $\begin{array}{c}\text { Initial modulus (MPa) } \\
\text { (Secant } 0.05 \%-0.25 \% \text { ) }\end{array}$ & $762 \pm 50$ & $974 \pm 62$ & +28 & $80 / 20$ & 1900 & 2800 & +47 & $20 / 80$ \\
\hline Stress at break (MPa) & $29.7 \pm 2.2$ & $78.1 \pm 2.9$ & +163 & $80 / 20$ & - & 150 & - & $20 / 80$ \\
\hline Strain at break $(\%)$ & $14.0 \pm 1.2$ & $10.4 \pm 1.5$ & -25 & $80 / 20$ & - & - & - & - \\
\hline
\end{tabular}


strated rather brittle behavior and none of them undergo necking during the tensile testing. This is possibly related, in addition to the known behavior of this polymer [14], with the large difference between the thickness $(60 \mu \mathrm{m}$ for the matrix and $220 \mu \mathrm{m}$ for the composite) and width $(15000 \mu \mathrm{m})$ of the tested specimens. Such a behavior could be advantageous for certain engineering plastics applications.

\section{CONCLUSION}

In summary, it can be concluded that polymorphism of polymers, particularly that of such a big and important family as polyamides [14] could be explored as an attractive approach for the manufacture of single polymer composites. This technique [9-12] as compared with the one-constituent hot compaction technique [2-8] has superior characteristics regarding the processing window. For example, the hot compaction of PA 66 has been carried out at temperatures between 260 and $263^{\circ} \mathrm{C}$ [3], while the compression molding of the polymorphic SPC from the same polymer was performed at $250^{\circ} \mathrm{C}$, i.e. some $10^{\circ} \mathrm{C}$ below the melting temperature of the reinforcement.

\section{ACKNOWLEDGEMENTS}

The authors would like to thank the Foundation for Research Science and Technology of New Zealand for their financial support (Grant No. UOAX 0406).

\section{REFERENCES}

[1] Capiati, N.J.; Porter, R.S. Concept of one polymer composites modeled with high-density polyethylene. J. Mater. Sci., 1975, 10(10), 1671-1677.

[2] Ward, I.M.; Hine, P.J. Polymeric materials. Brit Pat., GB2253420, 1992.
[3] Hine, P. J.; Ward, I. M. Hot compaction of woven nylon 6,6 multifilaments. J. Appl. Polym. Sci., 2006, 101(2), 991-997.

[4] Yan, R.J.; Hine, P.J.; Ward, I.M.; Olley, R.H.; Bassett, D.C. The hot compaction of SPECTRA gel-spun polyethylene fibre. $J$. Mater. Sci., 1997, 32(18), 4821-4832.

[5] Hine, P.J.; Ward, I.M.; Jordan, N.D.; Olley, R.; Bassett, D.C. The hot compaction behaviour of woven oriented polypropylene fibres and tapes. I. Mechanical properties. Polymer, 2003, 44(4), 11171131 .

[6] Hine, P.J.; Ward, I.M. Hot compaction of woven poly (ethylene terephthalate) multifilaments. J. Appl. Polym. Sci., 2004, 91(4), 2223-2233.

[7] Hine, P.J.; Astruc, A.; Ward, I.M. Hot compaction of polyethylene naphthalate. J. Appl. Polym. Sci., 2004, 93(2), 796-802.

[8] Ward, I. M.; Hine, P. J.; The science and technology of hot compaction. Polymer, 2004, 45(5), 1413-1427.

[9] Karger-Kocsis J. Verbundwerkstoff aus Polypropylenverstärkung und Polypropylenmatrix sowie verschiedene Verfahren zu dessen Herstellung. Ger Pat DE 10237803, 2007.

[10] Abraham, T.N.; Siengchin, S.; Karger-Kocsis, J. Dynamic mechanical thermal analysis of all-PP composites based on $\beta$ and $\alpha$ polymorphic forms. J. Mater. Sci., 2008, 43(10), 3697-3703.

[11] Banik, K.; Abraham, T.N.; Karger-Kocsis, J. Flexural Creep Behavior of Unidirectional and Cross-Ply All-Poly(propylene) (PURE®) Composites. Macromol. Mater. Eng., 2007, 292(12), 1280-1288.

[12] Banik, K.; Karger-Kocsis, J.; Abraham, T. Flexural creep of allpolypropylene composites: Model analysis. Polym. Eng. Sci., 2008, 48(5), 941-948.

[13] Bismarck, A.; Mishra, S.; Lampke, T. In Natural Fibres, Biopolymers, and Biocomposites; Mohanty, A.; Misra, M.; Drzal, L.T.; Eds.; CRC/Taylor \& Francis, USA, 2005, pp. 37-108.

[14] Aharoni, S.M.; n-Nylons: Their Synthesis, Structure, and Properties, John Wiley\&Sons Ltd., Chichester, 1997, p. 34

[15] Fakirov, S.; Avramova N. Applicability of Gibbs-Thompson equation to Nylon 6. J. Polym. Sci. Part C-Polym. Lett., 1982, 20(12), 635-641.

[16] Brandrup, J; Immergut, E.H.; Grulke E.A. Polymer Handbook, 4th ed., John Wiley \& Sons, New York, 1999.

(C) Duhovic et al.; Licensee Bentham Open.

This is an open access article licensed under the terms of the Creative Commons Attribution Non-Commercial License (http://creativecommons.org/licenses/by-nc/3.0/) which permits unrestricted, non-commercial use, distribution and reproduction in any medium, provided the work is properly cited. 